\title{
Clinical management of cutaneous adverse events in patients on targeted anticancer therapies and immunotherapies: a national consensus statement by the Spanish Academy of Dermatology and Venereology and the Spanish Society of Medical Oncology
}

\author{
C. Grávalos ${ }^{1}$ (D) O. Sanmartín ${ }^{2} \cdot$ A. Gúrpide ${ }^{3} \cdot$ A. España $^{4} \cdot$ M. Majem ${ }^{5} \cdot$ H. J. Suh $\mathrm{Oh}^{6} \cdot$ I. Aragón $^{7} \cdot$ S. Segura ${ }^{8}$. \\ C. Beato ${ }^{9} \cdot$ R. Botella ${ }^{10}$
}

Received: 3 July 2018 / Accepted: 11 September 2018 / Published online: 3 October 2018

(c) The Author(s) 2018

\begin{abstract}
Progress in the understanding of many tumors has enabled the development of new therapies, such as those targeted at specific molecules involved in cell growth (targeted therapies) or intended to modulate the immune system (immunotherapy). However, along with the clinical benefit provided by these new treatments, new adverse effects have also appeared. Dermatological toxicities such as papulopustular eruptions, xerosis, and pruritus are common with EGFR inhibitors. Other adverse effects have also been described with PDGFR, BCR-ABL, and MAPK tyrosine kinase inhibitors, antiangiogenic drugs, and inhibitors at immune checkpoints such as CTLA-4 and PD-1/PD-L1. Onset of these adverse effects often causes dose reductions and/or delays in administering the prescribed therapy, which can affect patient survival and quality of life. It is, therefore, important to prevent the occurrence of these adverse effects, or to treat unavoidable ones as soon as possible. This requires cooperation between medical oncologists and dermatologists. This article reviews the various dermatological toxicities associated with targeted therapies and immunotherapies, along with their diagnosis and therapeutic management.
\end{abstract}

Keywords Targeted therapies · Antiangiogenic drugs · Immune checkpoint inhibitors · MTOR inhibitors · Anti-EGFR · Dermatological toxicity

\section{Introduction}

Recent progress in the understanding of cancer biology, processes involved in carcinogenesis and neoangiogenesis, the tumor/stroma relationship, proliferation, and invasion, signaling pathways and the immune response has enabled

C. Grávalos

cgravalos@telefonica.net

1 Medical Oncology Department, Hospital Universitario 12 de Octubre, Avenida de Córdoba km 5.4, 28041 Madrid, Spain

2 Dermatology Department, Instituto Valenciano de Oncología, Valencia, Spain

3 Medical Oncology Department, Clínica Universitaria de Navarra, Pamplona, Spain

4 Dermatology Department, Clínica Universitaria de Navarra, Pamplona, Spain

5 Medical Oncology Department, Hospital de la Santa Creu i Sant Pau, Barcelona, Spain the development of drugs aimed at molecular targets. Targets of particular interest include EGFR (epidermal growth factor receptor), HER-2, RAS, BRAF, MEK, KIT, RET, mTOR (mammalian target of rapamycin), and VEGFR (vascular endothelial growth factor receptor) 1,2 , and 3 . These new

6 Dermatology Department, Complejo Hospitalario Universitario de Pontevedra, Pontevedra, Spain

7 Medical Oncology Department, Complejo Hospitalario Universitario de Huelva, Huelva, Spain

8 Dermatology Department, Hospital del Mar, Barcelona, Spain

9 Medical Oncology Department, Hospital Universitario Virgen Macarena, Sevilla, Spain

10 Dermatology Service, Instituto de Investigación Sanitaria La Fe, Valencia, Spain 
therapies include tyrosine kinase inhibitors (TKI), monoclonal antibodies, and cancer immunotherapies.

The dermatological effects they cause seem to be more common than those produced by conventional cytostatics and have specific clinical and pathological features $[1,2]$. EGFR inhibitors are routinely used to treat advanced malignancies such as colorectal cancer and lung cancer. Because of their mechanism of action and the targets they attack, they are very often associated with the development of dermatological adverse effects, which need to be understood and managed [3, 4]. However, it must be borne in mind that other drugs, directed against targets other than EGFR, also cause cutaneous toxicity.

Symptoms and esthetic issues can both have a major impact on patients' quality of life. Patients' personal, social, and workplace relationships can be affected. As with conventional chemotherapy, the dermatological side effects of targeted therapies can cause dose reductions and delays, or even treatment discontinuation. Accurate diagnosis of these adverse effects is, therefore, necessary, and in many cases therapeutic measures to reduce their severity and duration must be introduced as soon as possible [5, 6]. Preventive measures should be applied whenever they exist. Also, multidisciplinary assessment by dermatologists and medical oncologists is key to caring for these patients.

This article reviews the dermatological toxicity associated with the most commonly used TKIs, monoclonal antibodies, and immunotherapies, together with the clinical features, diagnosis, and therapeutic management involved with each of them.

\section{Classification of targeted therapies and immunotherapies, and mechanism of action of cutaneous toxicity}

The cancer treatment scene has been revolutionized by the advent of new targeted therapies and immunotherapy (Table 1). One of their most common side effects is cutaneous toxicity, the features of which differ according to each drug's mode of action.

\section{Targeted therapies}

\section{EGFR inhibitors}

The most important EGFR inhibitors belong to the following major therapeutic classes:

- Monoclonal antibodies: cetuximab, panitumumab, and necitumumab;

- Tyrosine kinase inhibitors:

- EGFR TKIs (gefitinib, erlotinib, and osimertinib);

- Dual EGFR and HER-2 TKIs (lapatinib and afatinib);

- Multikinase inhibitors (vandetanib).

\section{Antiangiogenic drugs}

The two main classes of antiangiogenic drugs are:

Table 1 Classification of targeted therapies and immunotherapies

Targeted therapies

EGFR inhibitors

KIT and BCR-ABL inhibitors

Antiangiogenic agents

RAS-RAF-MEK-ERK pathway inhibitors

Hedgehog pathway inhibitors

Immunotherapy

Anti-PD-1

Anti-PD-L1

Anti-CTLA-4

\author{
Monoclonal antibodies against EGFR: cetuximab, necitumumab, and panitumumab \\ EGFR-specific TKIs: erlotinib, gefitinib, and osimertinib \\ Dual EGFR and HER-2 kinase inhibitors: lapatinib, afatinib \\ Less specific multi-kinase inhibitors: vandetanib \\ Imatinib, dasatinib, ponatinib, nilotinib, and bosutinib \\ Monoclonal antibodies against VEGFR: bevacizumab, ramucirumab, and afliber- \\ cept \\ Non-selective antiangiogenic agents: sorafenib, sunitinib, pazopanib, regorafenib, \\ axitinib, lenvatinib, cabozantinib, and nintedanib \\ BRAF inhibitors: vemurafenib and dabrafenib \\ MEK inhibitors: cobimetinib, selumetinib, and trametinib \\ mTOR inhibitors: sirolimus, everolimus, and temsirolimus \\ Vismodegib \\ Nivolumab, pembrolizumab \\ Atezolizumab, durvalumab, avelumab \\ Ipilimumab, tremelimumab
}

CTLA-4 cytotoxic T-lymphocyte antigen 4, EGFR epidermal growth factor receptor, mTOR mammalian target of rapamycin, $P D-1$ programmed death 1, $P D-L 1$ programmed death-ligand 1, TKI tyrosine kinase inhibitor, VEGFR vascular endothelial growth factor receptor 
- Monoclonal antibodies (bevacizumab, aflibercept, and ramucirumab);

- Non-selective multikinase inhibitors (sorafenib, sunitinib, pazopanib, regorafenib, axitinib, lenvatinib, cabozantinib, and nintedanib).

Multikinase inhibitors characteristically act via several pathways, e.g. the platelet-derived growth factor receptor (PDGFR), c-KIT, fibroblast growth factor receptor (FGFR), RET, and VEGF pathways. The cutaneous toxicity seen with multikinase inhibitors reflects the promiscuity of these molecules, because it derives from their activity on receptors other than the VEGF receptors.

\section{KIT, PDGFR, and BCR-ABL TKIs}

The most important drugs in this class are imatinib, dasatinib, ponatinib, nilotinib, and bosutinib.

\section{MAPK inhibitors (RAS-RAF-MEK-ERK pathway)}

Mitogen-activated protein kinase (MAPK) inhibitors can be divided into three drug classes:

- BRAF inhibitors (vemurafenib, dabrafenib, and encorafenib);

- MEK inhibitors (trametinib, cobimetinib, and binimetinib);

- PI3K-AKT-mTOR pathway inhibitors (sirolimus, everolimus, and temsirolimus).

\section{Hedgehog pathway inhibitors}

The main representative of this class of inhibitors is vismodegib.

\section{Immune checkpoint inhibitors}

The main immune checkpoints are cytotoxic T-lymphocyte antigen 4 (CTLA-4), programmed death-ligand 1 (PD-L1), and programmed death 1 (PD-1). Inhibitors for each are as follows:

- Anti-CTLA-4 (ipilimumab and tremelimumab);

- Anti-PD-1 (nivolumab and pembrolizumab);

- Anti-PD-L1 (atezolizumab, durvalumab, and avelumab).

\section{Papulopustular eruption and xerosis cutis}

Both papulopustular eruption and xerosis cutis can occur after anti-EGFR drugs or mTOR inhibitors are used.
The underlying mechanism by which these drugs cause papulopustular eruption or xerosis cutis is not clear.

\section{Anti-EGFR drugs}

EGFR is mainly expressed and activated in basal keratinocytes and in the outer root sheath of hair follicles [7]. Arrested hair follicle growth and differentiation as a consequence of therapy can cause mechanical breakage of the hair follicle, generating hyperkeratosis and follicular plugging [8]. Anti-EGFR drugs can also affect cytokine production, resulting in leukocyte chemotaxis and infiltration into the skin [9], as well as changes in the skin microflora, giving rise to an inflammatory reaction [10].

\section{Papulopustular eruption}

Anti-EGFR drug-related papulopustular eruption is characterized by the presence of pruritic papules and pustules, typically distributed in seborrheic areas: The scalp, the face, behind the ears, in the mid-chest region, and on the shoulders and upper third of the back (Fig. 1a, b). It differs from acne in the absence of comedones and the presence of associated functional symptoms, such as a burning sensation, pruritus or pain. Its location in a highly visible area like the face has a major impact on the patient's emotional and social life. It develops during the first and second weeks of therapy and peaks between weeks 4 and 6 . The eruption tends to resolve in approximately 8 weeks, leaving erythema and post-inflammatory inflammation (Fig. 1a, b).

Treatment for this condition will depend on the severity (Table 2). Any therapeutic management must always be accompanied by general recommendations: Avoid soaps and perfumes, moisturize the skin daily, and apply photoprotection measures (avoid exposure to the midday sun, wear appropriate clothing, and use a sunscreen with a high UVA + UVB protection factor). For treating localized papulopustular lesions, clindamycin $1 \%$ lotions or emulsions and moderately to highly potent topical corticosteroids are recommended. In more extensive cases (grade 2 toxicity), oral antibiotics such as doxycycline or minocycline are used. In recalcitrant cases, some authors have documented the usefulness of oral retinoids, although xerosis and photosensitivity may worsen in some individuals [11]. Patients who also have seborrheic dermatitis of the scalp may benefit from shampoos containing ciclopirox olamine $1.5 \%$, ketoconazole $2 \%$, pyrithione zinc $1 \%$, selenium sulfide, coal tar $0.5 \%$ or salicylic acid $3-5 \%$ preparations.

The eruption caused by anti-EGFR drugs is initially sterile, but it is not uncommon for it to be superinfected by Staphylococcus aureus, occasionally $S$. aureus resistant to methicillin (MRSA), tetracycline or clindamycin. Herpes simplex virus infections are rarely encountered [12]. 

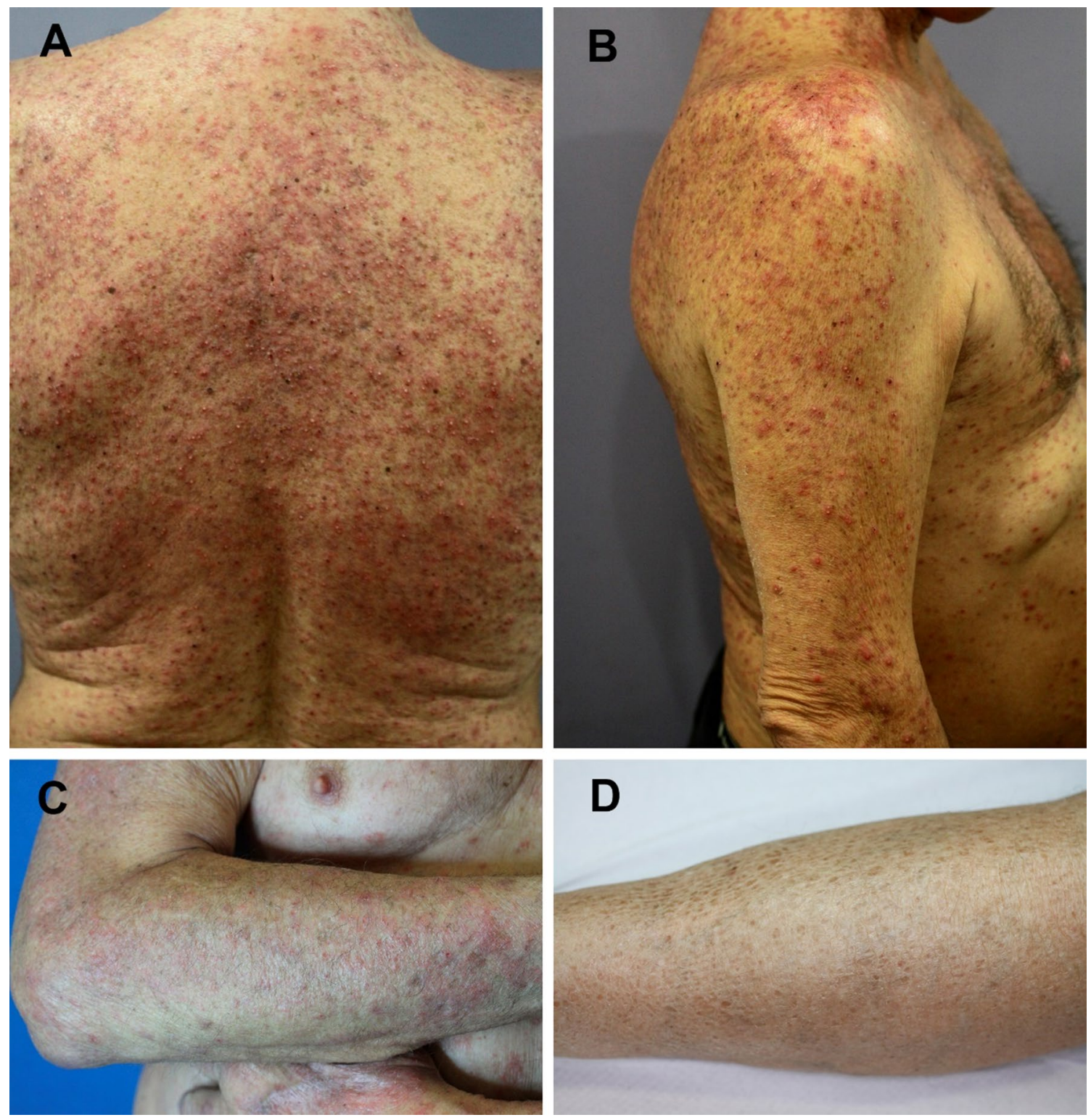

Fig. 1 Papulopustular eruption on the trunk and arms of a patient treated with cetuximab for colorectal carcinoma $(\mathbf{a}, \mathbf{b})$. Eczematous eruption in a patient treated with gefitinib for non-small-cell lung

cancer (c), Xerosis cutis with skin of an ichthyosis-like appearance in a patient treated with everolimus $(\mathbf{d})$

Faced with a recalcitrant or atypical eruption, or one that lasts longer than 8 weeks, bacterial cultures and virological tests are recommended, to rule out superinfection and institute specific treatment [13]. To prevent secondary infection, some authors recommend 10-minute baths in dilute bleach (a quarter of a cup of household bleach in a bathtub) [13].

The severity of papulopustular eruption has been linked to greater overall survival [14-16], with a $60 \%$ decrease in the risk of death according to a recent meta-analysis [17].

The prophylactic role of tetracyclines has been examined in four clinical trials, and the following are recommended: minocycline $100 \mathrm{mg}$ once daily, doxycycline $100 \mathrm{mg}$ once or twice daily, and tetracycline $500 \mathrm{mg}$ twice daily. In all cases, prophylactic treatment has reduced the incidence of grade 2 or grade 3 eruptions [18]. Some groups recommend phytomenadione (vitamin $\mathrm{K}$ ) as a topical therapy to prevent acneiform eruption [19].

\section{Xerosis and pruritus}

Xerosis cutis occurs in up to $35 \%$ of patients treated with anti-EGFR drugs [20]. Deregulation of epidermal differentiation during anti-EGFR therapy gives rise to an abnormal stratum corneum and poor sebaceous gland function, which 


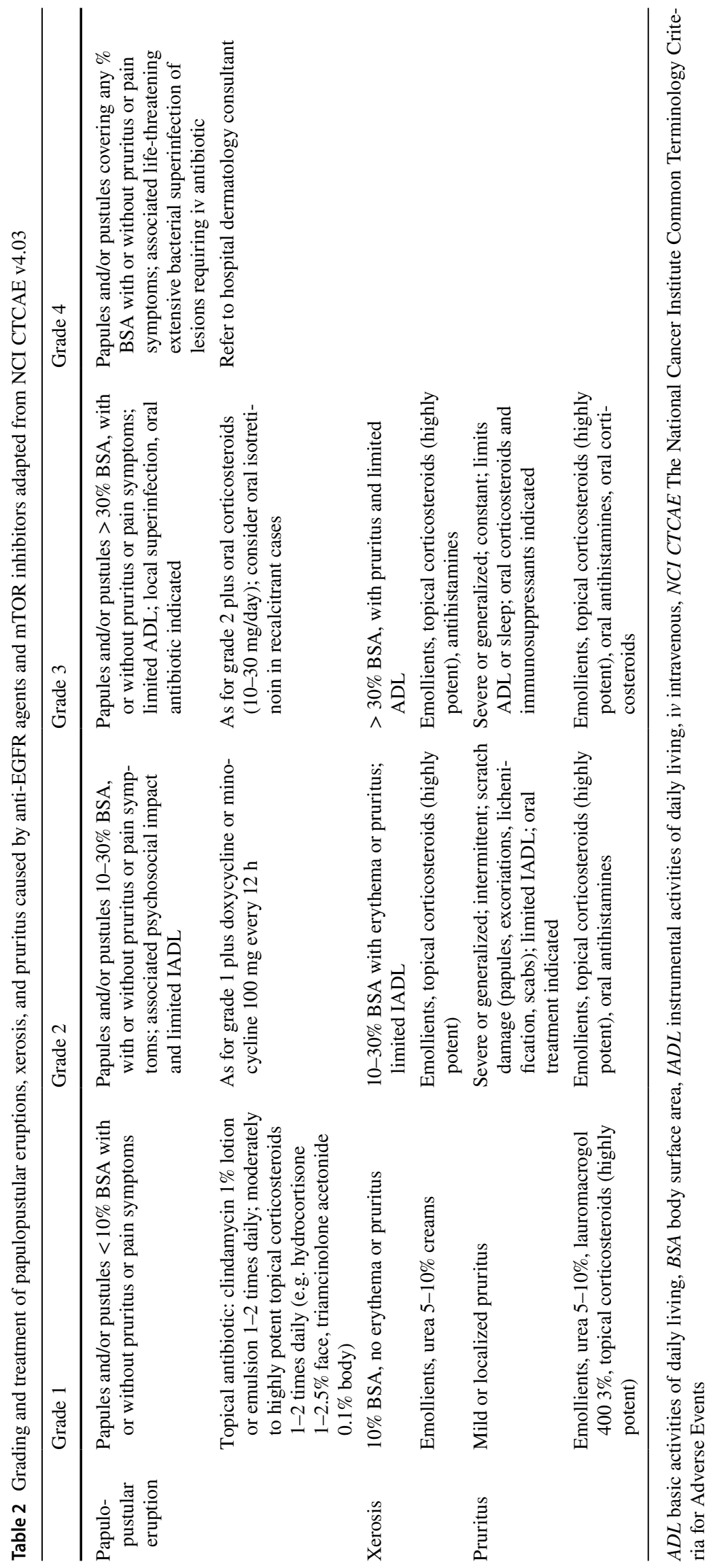


results in dry skin [20]. Elderly patients with a history of atopic eczema, and individuals previously treated with cytotoxic agents, are most likely to develop xerosis. It presents as dry, desquamative skin, with an itching sensation. It is particularly located in areas simultaneously or previously affected by papulopustular eruption. Xerosis can progress to chronic asteatotic eczema, with erythematous, desquamative plaques on the trunk and extremities (Fig. 1c). It can sometimes be superinfected by $S$. aureus and, more rarely, by herpes simplex virus 1 [10].

Treatment for this condition will depend on its severity and extent (Table 2). It essentially involves not applying any irritant products to the skin (soaps, perfumes), using oils and detergent-free hygiene products, showering in lukewarm water, and applying emollient creams daily to help rebuild the skin barrier.

Pruritus is suffered by $18-55 \%$ of patients on anti-EGFR therapy, and the risk is highest with panitumumab [21]. Pruritus tends to be associated with papulopustular lesions, xerosis cutis or asteatotic eczema. Other factors, such as concomitant medication, comorbidities or the underlying malignancy itself, can influence the presence of pruritus. In cases of mild to moderate pruritus, topical corticosteroids, emollient preparations containing antipruritic substances, and oral antihistamines can be used. Severe pruritus requires oral treatment with antihistamines and corticosteroids, and sometimes other drugs with an antipruritic effect, such as antidepressants, anticonvulsants and aprepitant [21].

\section{mTOR inhibitors}

The inflammatory cutaneous eruptions that occur as a consequence of using these drugs are seen in up to $25 \%$ of patients on everolimus ( $<1 \%$ grade $\geq 3)$ and up to $46 \%$ of those on temsirolimus ( $3 \%$ grade $\geq 3$ ) [22]. Morbilliform, eczematous, and papulopustular eruptions can occur, sometimes in combination with xerosis (Fig. 1d) and pruritus. Papulopustular cutaneous eruption occurs during the first 2 weeks of therapy. It mainly affects the trunk, followed by the extremities, neck, face, and scalp. Grading and treatment strategies are similar to those recommended for anti-EGFR drug-induced eruption (Table 2) [22, 23]. Another similarity to anti-EGFR drugs is that the presence of mucocutaneous toxicity has been associated with a better prognosis in patients with metastatic renal cell carcinoma treated with everolimus [24].

\section{Acral erythema}

\section{Differences between acral erythema caused by targeted therapies and by conventional chemotherapy}

Like conventional chemotherapy, targeted therapies often affect the skin on the palms of the hands and the soles of the feet. However, there are important differences between acral erythema caused by targeted therapies and by chemotherapy, as summarized in Table 3. Acral erythema induced by conventional chemotherapy is a dose-dependent reaction, caused by direct epidermal cytotoxicity. It manifests with erythema, edema, fissuring, and blistering [25]. With conventional chemotherapy, palmar-plantar involvement is often associated with other cutaneous lesions grouped together under the term "toxic erythema of chemotherapy" [26]. In contrast, TKI-induced hand-foot syndrome manifests with hyperkeratotic lesions on the palms and soles that are more severe at pressure points. Although this too is a dose-dependent reaction, the pathogenic mechanism has not been fully explained [27]. The hand-foot syndrome caused by multikinase inhibitors shows no significant association with other cutaneous eruptions.

\section{Epidemiology}

Hand-foot syndrome is the most common of the cutaneous adverse events caused by TKIs. Table 4 lists the drugs most often responsible for hand-foot syndrome [27-30].

Table 3 Differences between multikinase inhibitor-induced hand-foot syndrome and acral erythema caused by conventional chemotherapy

\begin{tabular}{lll}
\hline & Hand-foot syndrome & Acral erythema \\
\hline Common causative agents & $\begin{array}{c}\text { Regorafenib, cabozantinib, sorafenib, axitinib, sunitinib, } \\
\text { vemurafenib, pazopanib } \\
\text { VEGFR and PDGFR blockade, difficulty repairing } \\
\text { microtrauma }\end{array}$ & $\begin{array}{c}\text { Docetaxel, paclitaxel, liposomal doxorubicin, capecit- } \\
\text { abine, fluorouracil, vinorelbine } \\
\text { Directly cytotoxic to epidermis and eccrine glands }\end{array}$ \\
Site of lesions & Palms and soles & Palms and soles, occasionally dorsum of hands and feet \\
Clinical features & $\begin{array}{l}\text { Hyperkeratotic lesions at pressure points } \\
\text { Acanthosis, hyperkeratosis, ballooning degeneration of } \\
\text { the epidermis, subepidermal blisters }\end{array}$ & $\begin{array}{l}\text { Erythema, edema, fissuring, blistering } \\
\text { Cell-poor interface dermatitis, epidermal atrophy, } \\
\text { keratinocyte necrosis, subepidermal blisters with } \\
\text { epidermal necrosis }\end{array}$ \\
\hline
\end{tabular}

PDGFR platelet-derived growth factor receptor, VEGFR vascular endothelial growth factor receptor 
Table 4 TKIs responsible for hand-foot syndrome

\begin{tabular}{llll}
\hline Drug & Targets & $\begin{array}{l}\text { Overall incidence of hand- } \\
\text { foot syndrome (\%) }\end{array}$ & $\begin{array}{l}\text { Incidence of hand-foot } \\
\text { syndrome as DLT (\%) }\end{array}$ \\
\hline Regorafenib [30, 36] & $\begin{array}{l}\text { VEGFR-1, 2 and 3; TIE-2; FGFR-1; PDGFR- } \alpha \text {, } \beta \text {; c-KIT; } \\
\text { RET; RAF; MAPK }\end{array}$ & 60.5 & 20.4 \\
Cabozantinib [26, 27] & VEGFR-2; c-MET; RET; c-KIT; FLT3; TIE-2 & 35.3 & 9.5 \\
Sorafenib [29, 35] & VEGFR-2 and 3; PDGFR; ARAF; BRAF; CRAF; FLT3 & 33.8 & 8.9 \\
Axitinib [25] & VEGFR-1, 2, and 3 & 29.2 & 9.6 \\
Sunitinib [29] & VEGFR-2; PDGFR; c-KIT; FLT3 & 18.9 & 5.5 \\
Vemurafenib [28] & BRAF & 8.7 & 2.0 \\
Pazopanib [27] & RAF; VEGFR-2 and 3; PDGFR- $\beta$; c-KIT; FLT3; RET & 4.5 & 1.8 \\
\hline
\end{tabular}

$D L T$ dose-limiting toxicity, FGFR fibroblast growth factor receptor, $M A P K$ mitogen-activated protein kinase, $P D G F R$ platelet-derived growth factor receptor, $V E G F R$ vascular endothelial growth factor receptor

\section{Pathogenesis}

The pathogenic mechanism of hand-foot syndrome is unknown, although it has been linked to VEGFR and PDGFR blockade. It is possible that a defect may occur in vascular microtrauma repair, which would explain the tendency for lesions to be located at sites subjected to friction [31]. Accordingly, the higher incidence of hand-foot syndrome in patients on regorafenib, which uniquely inhibits the endothelium-specific TIE-2 receptor (essential in vascular remodeling), supports the importance of vascular competence in the pathogenesis of this syndrome [30].

\section{Clinical features}

This is a dose-dependent reaction that occurs in the first 2-4 weeks of therapy and increases in severity towards the second and third months of therapy. The clinical features usually tend to abate gradually as treatment continues [27, 30]. The lesions are located at pressure points on the palms and soles, although they can affect other areas subjected to friction, such as the knuckles or the sides of the feet. These lesions consist of hyperkeratotic plaques situated on an erythematous background, which may even blister in the most severe cases. Clinical features include pain and discomfort, such as paresthesia, a burning sensation, and reduced heat tolerance.

Although hand-foot syndrome is not life-threatening, the severity of the discomfort can seriously impair patients' quality of life, and it is a frequent cause of dose reductions or early treatment discontinuation.

The severity grading for hand-foot syndrome according to the Common Terminology Criteria for Adverse Events (CTCAE) is the same as for palmar-plantar erythrodysesthesia caused by conventional chemotherapy. Three grades are recognized [32]: Grade 1 means the presence of minimal skin changes (erythema, edema or hyperkeratosis) without associated pain; grade 2 means painful cutaneous lesions (blisters, bleeding, edema or hyperkeratosis) hindering everyday activities; and grade 3 entails painful severe cutaneous lesions that make self-care impossible.

\section{Treatment}

The tendency should be towards personalized, multidisciplinary treatment, involving the medical oncologist, dermatologist, podiatrist, and nursing staff. Currently, there are no controlled clinical trials available that demonstrate the advantages of one treatment over another [33]. Preventive measures are important, such as using suitable footwear (padded and exerting no pressure), podiatric care, good hygiene, applying emollient creams, and avoiding contact with anything hot [34]. Gentle keratolytics, such as urea $10 \%$ or salicylic acid 5\%, can be used on hyperkeratotic lesions. Erosive or blistered lesions can be treated with hydrocolloid dressings. Highly potent topical corticosteroids (clobetasol propionate $0.05 \%$ ) can be used in cases of grade 2 or 3 severity [34]. Pain is treated with non-steroidal anti-inflammatory drugs or gamma-aminobutyric acid (GABA) agonists. Patients with grade 2 or 3 toxicity tend to require treatment discontinuations or dose adjustments according to the protocol for each drug.

\section{Multikinase inhibitor-induced exanthematous reactions}

Multikinase inhibitor drugs often give rise to dose-dependent rashes during the first few weeks of therapy [29, 35-37]. Unlike the papulopustular eruption seen with anti-EGFR drugs, these eruptions are unrelated to efficacy. Multikinase inhibitor-induced rashes are not well characterized in the literature and are usually described as non-specific rashes. They consist of diffuse mild eruptions of a morbilliform, eczematous or lichenoid nature, and tend to resolve spontaneously despite continued therapy (Fig. 2). They must be 

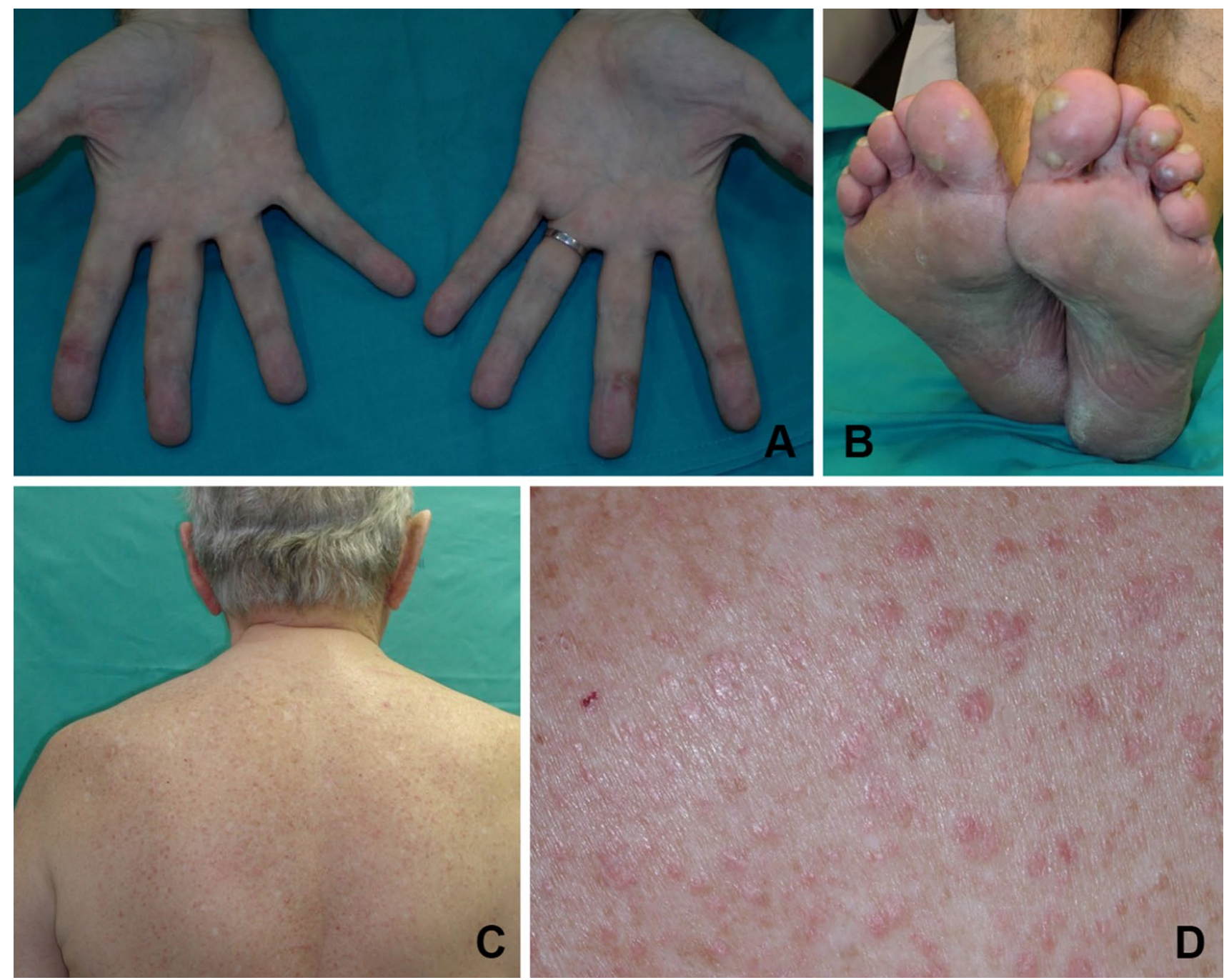

Fig. 2 Sorafenib-induced hand-foot syndrome. Hyperkeratotic lesions on an erythematous background located above pressure points (a, b). Sunitinib-induced rash and desquamative maculopapular rash distributed on the trunk (c, d)

distinguished from other much less common, more serious eruptions related to drug hypersensitivity, such as erythema multiforme, hypersensitivity syndrome, exanthematous pustulosis, Stevens-Johnson syndrome or toxic epidermal necrolysis. These have all been described occasionally in the past with one multikinase inhibitor or another.

Multikinase inhibitor-induced rash is very common. It occurs in $20-30 \%$ of patients on sorafenib, regorafenib or imatinib therapy, $10-20 \%$ of patients on sunitinib, and $5-10 \%$ of those on pazopanib therapy. It arises during the first 6-8 weeks of treatment and consists of mild eruptions (grade 1-2) involving less than $30 \%$ of the body surface area. The lesions are mainly distributed on the trunk and the tops of the limbs. In most cases, the eruptions are eczematous and become morbilliform in appearance. Less often, they can present as lichenoid lesions. Generally, these eruptions are mild (grade 1-2) and do not require withdrawal of the drug.
If symptomatic treatment elicits a good response, therapy can be allowed to continue. The accompanying symptoms tend to be pruritus and, occasionally, a pricking sensation. Symptomatic treatment with oral antihistamines and moderately potent topical corticosteroids is usually sufficient.

\section{EGFR and BRAF inhibitor-induced abnormalities of the hair follicle and nail apparatus}

Normal EGFR expression in the epidermis, eccrine glands, and hair follicles can encourage development of the PRIDE complex (papulopustules, paronychia, regulatory abnormalities of the hair follicle, pruritus and dry skin) [38] during therapy with EGFR inhibitors. The onset of pustular acneiform folliculitis without comedones, sometimes with 
pruritus, occurs on the scalp, face, and trunk in over $50 \%$ of cases (Fig. 3a), especially during cetuximab and panitumumab therapy, when it is seen in up to $100 \%$ of cases [10]. This abnormality is usually more severe with the administration of monoclonal antibodies than with TKIs, and it develops a week after treatment starts. Although most eruptions are grade 1 or 2 , higher severity tends to be associated with a better tumor response to therapy $[4,10,38]$.

Cultures obtained from the lesions are usually negative but increased expression of $\mathrm{p} 27^{\mathrm{Kip} 1}$ in follicular lesions has been demonstrated [39]. These lesions, in turn, might be due to deregulation of pathways involving IL-1 [40]. Administering benzoyl peroxide, metronidazole or clindamycin, or adding tetracyclines, oral isotretinoin, or even stopping the anti-EGFR drug are the treatment regimens that tend to be used most $[4,10,38]$.

EGFR inhibitors have also been associated with elongation (trichomegaly) (Fig. 3b) or fragility of the eyelashes, and with more brittle, finer, wavy, and fragile hair [41]. BRAF inhibitors, such as vemurafenib, can cause alopecia in up to $36 \%$ of cases [42]. Last, xerosis cutis may develop
[4, 10, 38], with substantial morbidity [20], with fissuring of the heels (Fig. 3c) or fleshy parts of the digits (Fig. 3d) 4-8 weeks after therapy with the inhibitor begins [10].

Another side effect related to drugs that inhibit EGFR, albeit uncommon, is the onset of nail abnormalities 4-8 weeks after therapy starts. These take the form of fragility, onychoschizia, onychorrhexis or onycholysis. Only $10-15 \%$ of cases may develop paronychia (Fig. 3e), sometimes with $S$. aureus superinfection [10].

\section{Pigmentation changes with the administration of targeted therapies}

Pigmentary changes are commonly seen with the administration of targeted therapies and are often characteristic. Essentially, they consist of depigmentation of the hair and, to a lesser extent, the skin or its appendages. The c-KIT protein is involved in melanocyte physiology, regulating melanogenesis and melanocyte proliferation, migration,
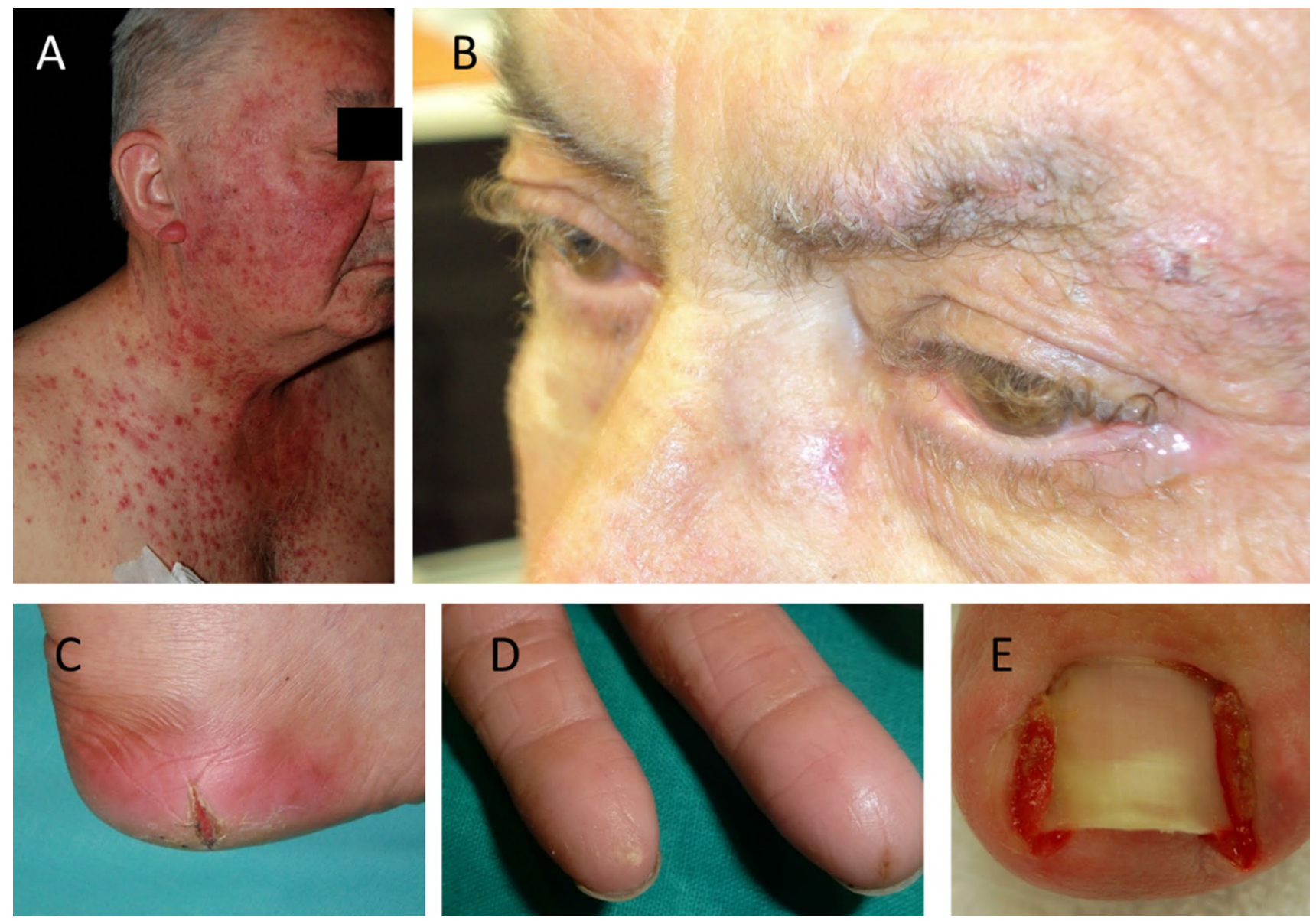

Fig. 3 EGFR inhibitors can cause acneiform folliculitis on the head and trunk (a), elongated eyelashes (trichomegaly) with possibly increased eyebrow growth (b), fissures on the heels (c) and fleshy parts of the digits (d), and increased periungual granulation tissue with inflammation (e) 
and survival [43]. Imatinib can cause cutaneous hypopigmentation or depigmentation in up to $40 \%$ of patients, most commonly those with a high phototype [44]. In some cases, bluish pigmentation of the oral cavity may be observed [45]. Cutaneous depigmentation may be localized or diffuse. It develops after several weeks of therapy and usually disappears when treatment ends. In some cases, worsening of pre-existing vitiligo, or even hyperpigmentation, has been described (Fig. 4a) [46]. Nilotinib and dasatinib can also cause pigmentary changes, but less frequently [47].

Sunitinib is a mixed TKI that can produce depigmentation of the hair, eyebrows or eyelashes after several weeks of therapy. This effect is characterized by alternating depigmented and pigmented zones on the same hair shaft, corresponding to weeks of therapy and rest periods, respectively. It is also common for a yellowish coloration to develop, especially on the facial skin and oral mucosa. These changes usually resolve when treatment ends [48].

The multikinase inhibitor vandetanib can induce the onset of blue-gray macules measuring a few millimeters (blue dots), predominantly in perifollicular regions of the face and trunk. They tend to persist or recur with maintenance therapy [49]. Pigmentary changes (hyperpigmentation or depigmentation) have also been described with immunotherapies (interferon, ipilimumab, nivolumab, pembrolizumab), MEK inhibitors, and other multi-kinase inhibitors, e.g. pazopanib
(Fig. 4b, c) [22]. RAF inhibitors (sorafenib, vemurafenib, dabrafenib, and regorafenib) can induce dynamic changes in pre-existing naevi or trigger the development of eruptive naevi (Fig. 4d). Dermatological surveillance is necessary in this context, because cases of de novo primary melanomas have been reported in patients treated with BRAF inhibitors [50].

\section{Impaired healing due to antiangiogenic drug use}

Inhibition of angiogenesis interferes with normal skin homeostasis. Among other complications, this can give rise to delays or difficulties in wound healing. Drugs that inhibit VEGF or VEGFR have the potential to cause these complications. Bevacizumab, an anti-VEGF antibody, is associated with a higher incidence of surgical wound complications (dehiscence and delayed healing). The incidence varies according to the context in which it is used. It is advisable to stop treatment with this drug at least 6-8 weeks before surgery and to wait until 4 weeks after surgery before resuming it [51]. The risk of complications with mTOR inhibitors is not negligible either. It is, therefore, advisable to stop therapy 7-10 days beforehand and to wait for at least 3 weeks after the intervention before resuming it. The risk seems to
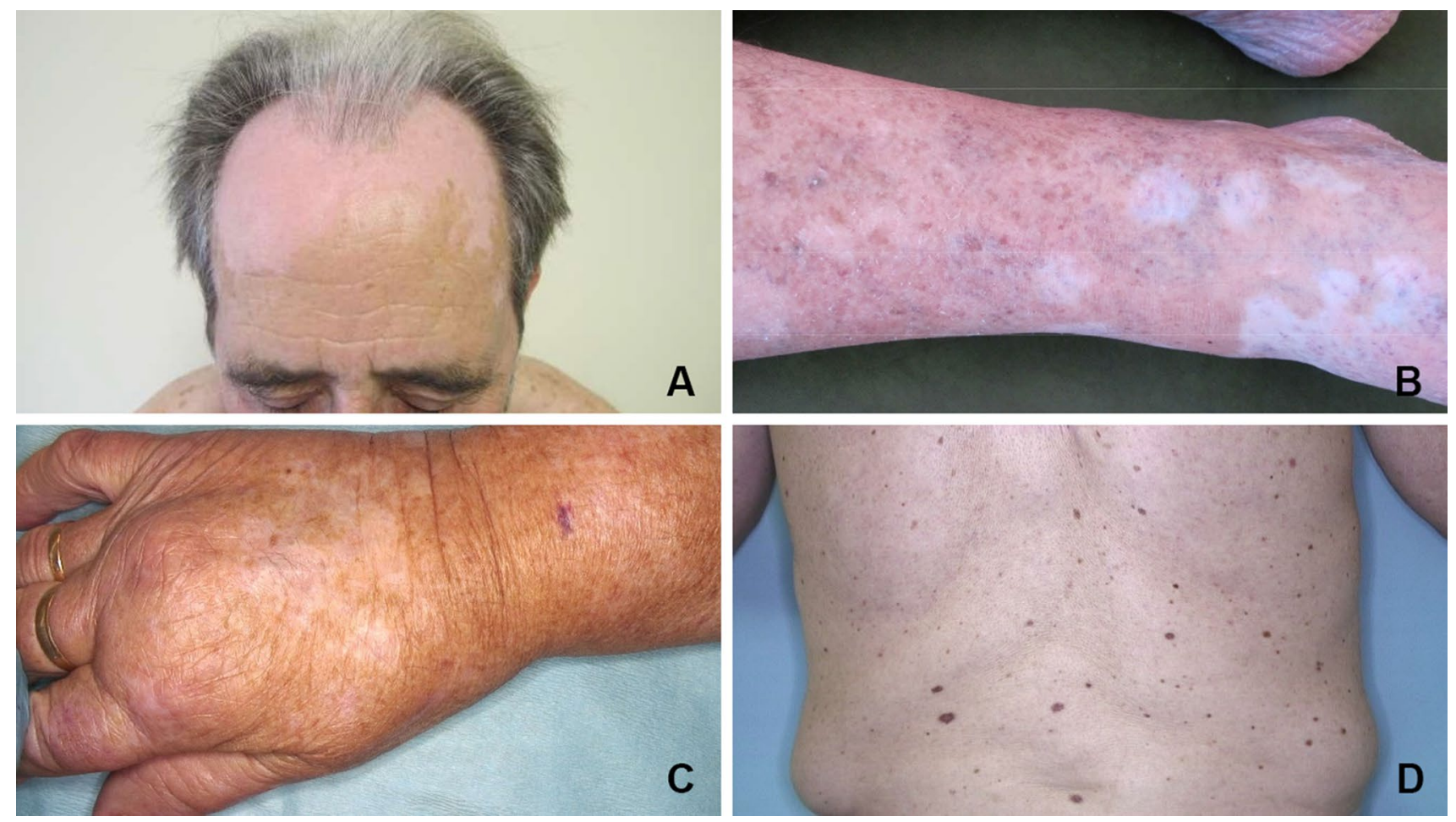

Fig. 4 Worsening of pre-existing vitiligo (a), immunotherapy-induced vitiligo and depigmentation (b, c), and BRAF inhibitor-induced eruptive naevi (d) 
be lower with TKIs. The recommendation is to stop them 24-48 $\mathrm{h}$ before surgery and to wait 3-4 weeks before resuming them [52]. In any case, good perioperative management, bearing in mind the elimination half-life of each drug, is essential to avoid these complications [53].

\section{Neutrophilic dermatosis}

The onset of various neutrophilic dermatoses has been described with the use of targeted therapies. TKIs, such as imatinib, nilotinib or dasatinib, have been linked to cases of Sweet's syndrome, neutrophilic eccrine hidradenitis, and neutrophilic panniculitis [54]. Pyoderma gangrenosum has also been linked to TKIs, EGFR inhibitors, and drugs such as ipilimumab or rituximab, among others [55]. Cases of neutrophilic eccrine hidradenitis and neutrophilic panniculitis have also been reported in patients on BRAF inhibitors (vemurafenib, dabrafenib). In most cases, treatment discontinuation tends not to be necessary [56].

\section{Cutaneous lesions caused by BRAF and MEK inhibitors}

In pivotal trials conducted with vemurafenib, a BRAF inhibitor, a high percentage of patients developed side effects, mainly of a cutaneous nature (92-95\%) [28]. Nevertheless, most of these effects are mild or moderate, and relatively easy to manage if well understood. Very few cases require modification or discontinuation of therapy. The occurrence or severity of these side effects has not been correlated with treatment efficacy.

The cutaneous side effect of greatest concern is the onset of skin tumors, specifically squamous cell carcinomas (Fig. 5a) and, in many cases, a well-differentiated variant of these with very little metastatic potential, called a keratoacanthoma. These tumors generally appear between weeks 2 and 36, most commonly between weeks 12 and 18. They have been reported in $20-30 \%$ of patients [22]. Surgical treatment for these tumors is usually simple. The administration of oral retinoids has been shown to reduce their frequency [57]. Their occurrence seems to be due to
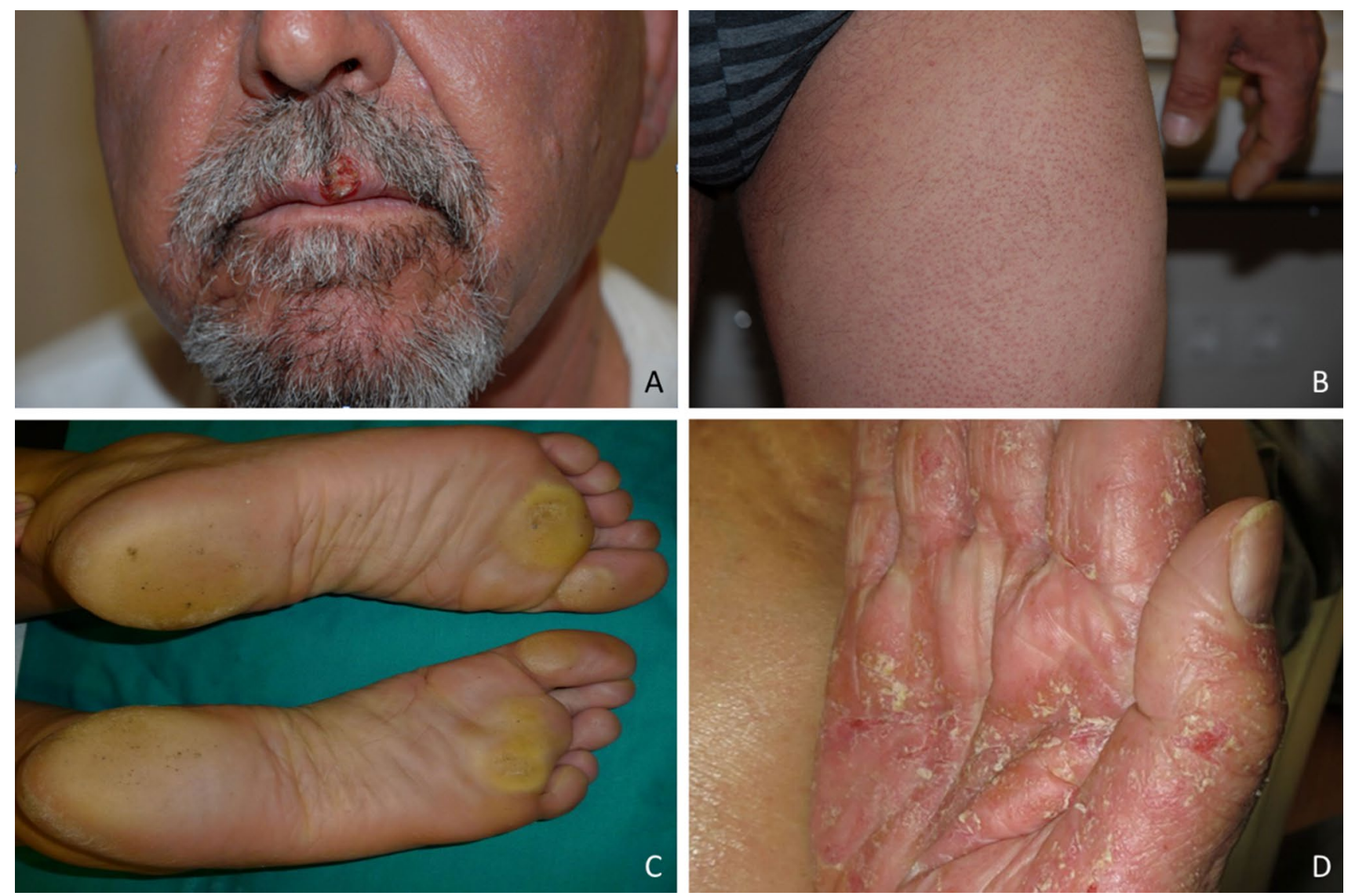

Fig. 5 A patient with squamous cell carcinoma of the upper lip, keratosis pilaris, and plantar keratoderma secondary to vemurafenib therapy (a, $\mathbf{b}$, and $\mathbf{c}$, respectively). Reactivation of psoriasis in a patient on pembrolizumab therapy (d) 
paradoxical stimulation of the MAPK pathway in BRAF wild-type cells [58]. This stimulation is especially important in cells that, because of sun exposure, already harbor mutations in RAS, the first kinase in this pathway. Other BRAF inhibitors developed subsequently, such as dabrafenib, cause cutaneous side effects, including squamous cell carcinomas, at a lower rate [59]. Introducing dual inhibition of the MAPK pathway with coadministered BRAF and MEK inhibitors has achieved a substantial reduction in the frequency at which these tumors occur, probably by inhibiting the paradoxical stimulation described above, by means of MEK inhibitor-induced blockade of the pathway downstream of BRAF [60]. The onset of both atypical melanocytic lesions and melanomas of low thickness has also been documented. These have been attributed to the same paradoxical MAPK pathway stimulation effect [61].

Despite the above, the most common cutaneous manifestation is a maculopapular rash (64-75\% of cases), often poorly described [28]. Of particular note is the follicular accentuation shown by the lesions in some cases, taking on the appearance of keratosis pilaris [22] (Fig. 5b). Other patients develop a rash composed of erythematous papules located on the chest, face, and upper limbs. Biopsy has demonstrated the existence of acantholysis and suprabasal dyskeratosis, findings consistent with Grover's disease (or transient acantholytic dyskeratosis) [62, 63]. These lesions have been attributed to paradoxical MAPK pathway activation in normal keratinocytes, causing decreased expression of the protein sarco/endoplasmic reticulum $\mathrm{Ca}^{2+}$-ATPase type 2 isoform (SERCA2), also involved in Darier's disease, which shares histological features in common with Grover's disease [63].

Photosensitivity is another common side effect of vemurafenib (35-63\% of patients) [28]. This drug stimulates erythrocyte 5-aminolaevulinic acid synthase (ALAS), raising porphyrin levels in red blood cells [64]. Photobiology tests have shown the photosensitivity to be due to a heightened reaction to ultraviolet rays (UVA), with a decrease in the UVA minimal erythema dose [64, 65]. Other less common side effects are: palmar-plantar erythrodysaesthesia (8-10\% of patients) [28]; palmar-plantar keratoderma (6-60\% of patients), which can cause substantial discomfort in daily life [22] (Fig. 5c); alopecia due to telogen effluvium; and changes in the appearance of the hair, ranging from turning gray to becoming curly [66].

One uncommon but very interesting side effect already mentioned above is the onset of neutrophilic dermatoses during the administration of BRAF inhibitors. There have been reports of lobular panniculitis, Sweet's syndrome, and neutrophilic eccrine hidradenitis [67-69].

Side effects related to MEK inhibitors (trametinib, cobimetinib) are less complex. The most common are papulopustular rashes (77-89\% of patients) and xerosis $(30 \%)$ [22, 62].

\section{Cutaneous lesions caused by cancer immunotherapy}

In the past few years, progress in the understanding of regulatory mechanisms governing the immune response has led to the development of monoclonal antibodies that deactivate inhibitory receptors expressed by T cells. Drugs that stimulate the immune response by inhibiting CTLA-4 (ipilimumab), PD-1 (nivolumab, pembrolizumab) or PD-L1 have thus appeared. However, the anticancer effect of these drugs is accompanied by a number of cutaneous and systemic side effects related to immune stimulation. In this class, cutaneous side effects are the most common, and they also tend to be the first to appear. Although their severity seems to be correlated with treatment efficacy, their absence does not imply lack of response. In general, they are reversible if treated promptly, and the administration of either systemic corticosteroids or anti-TNF drugs does not counteract the anticancer effect [70]. The most common cutaneous side effects are the same with either anti-CTLA-4 or anti-PD-1 drugs: maculopapular rash, pruritus, and vitiligo. They occur more often and are more severe with ipilimumab than with anti-PD-1 drugs.

In the case of ipilimumab, and unlike the situation with anti-PD-1 drugs, cutaneous side effects depend on the drug dose. The most common side effect is maculopapular rash (47-68\%) [62]. It tends to occur 2-5 weeks after therapy begins. Severe, life-threatening reactions, of the Stevens-Johnson syndrome, toxic epidermal necrolysis or DRESS syndrome type, have been reported at a frequency of less than 1\% [70]. Pruritus can occur on its own, or in the context of the above-mentioned rash, and may be severe enough to require dose reduction. Dermatomyositis, Sweet's syndrome, pyoderma gangrenosum, and sarcoidosis have been described during anti-CTLA-4 therapy, albeit uncommonly [71-74].

As far as the most common reactions related to antiPD-1 drugs are concerned, the maculopapular rash often acquires lichenoid features (lesions with a dark red tone and intense residual hyperpigmentation). A biopsy confirms lichenoid histology [75, 76]. On the other hand, achromic lesions resembling vitiligo have often been described. Unlike vitiligo, however, they tend to adopt a patchy distribution, occur more often in light-exposed areas, and do not display the Koebner phenomenon [77]. An ever-increasing number of publications describe patients who were diagnosed with pemphigoid after commencing anti-PD-1 therapy [78]. Last the triggering of psoriasis flare-ups has also been linked to this drug class, in most cases in patients with a history of this disease [79, 80] (Fig. 5d). 


\section{Grading cutaneous toxicity in cancer patients on targeted therapies and immunotherapy, and dose adjustments}

New cancer treatments, including immunotherapy, cause a range of cutaneous toxicities that can lead to dose changes or discontinuation of various drugs. The constant addition of new substances and their combinations, especially in clinical trials, poses a challenge, in terms of both grading toxicities and managing them with specific dermatological treatment. Notable scales for grading cutaneous toxicity include the Common Terminology Criteria for Adverse Events (CTCAE), Version 4.03 [32, 81], produced by the National Cancer Institute (NCI) and, more recently, the Multinational Association of Supportive Care in Cancer (MASCC) EGFR Inhibitor Skin Toxicity Tool (MESTT) [82].

The CTCAE and MESTT scales grade dermatological toxicities from 1 to 5 . As a general rule, a grade 1 toxicity is asymptomatic or involves few symptoms, which only requires diagnostic and clinical observation, and needs no specific treatment. Grade 2 or moderate toxicity requires non-invasive, local treatment. Grade 3 is severe, and the patient must be admitted to hospital. Grade 4 requires urgent treatment for a life-threatening condition, and Grade 5 means the patient died from the adverse effect.

The dermatological toxicity most often seen with targeted therapies relates to anti-EGFR drugs. It is caused by EGFR inhibition in the skin, and the most common form is papulopustular eruption [83, 84]. With immunotherapies, dermal toxicity occurs in $40-45 \%$ of patients, normally between weeks 3 and 6 of therapy $[85,86]$. Whether to adjust or delay the dose or discontinue treatment is specified in the prescribing information for each drug. In general, we describe the steps to be taken according to drug class and the most representative toxicities. For EGFR inhibitors, the dose should be adjusted after the onset of cutaneous toxicity of grade 3 or above, or intolerable grade 2 toxicity. In these cases, treatment should be discontinued temporarily until the toxicity subsides to grade 1 or 2 , respectively. It should then be resumed at a lower dose [87].

Monoclonal antibodies against VEGF/VEGFR cause delayed healing. The most representative drug of this class is bevacizumab. Withdrawal is recommended 6-8 weeks prior to planned surgery, followed by reintroduction 4 weeks after the operation. In the antiangiogenic drug class, in the case of multikinase inhibitors, it is recommended that therapy be discontinued $24-48 \mathrm{~h}$ prior to surgery, and 3-4 weeks should elapse before treatment resumes [52]. In all cases, therapy should stop until the wound is completely healed.

Hand-foot syndrome is also common and limiting with this drug class. Dose reduction is recommended if it occurs at grade 2. If it persists, or reaches grade 3 or above, the drug should be discontinued until the condition improves.

In the case of the RAF inhibitors vemurafenib and dabrafenib, the onset of cutaneous squamous cell carcinomas and new primary melanomas is managed by monitoring these new lesions and removing them surgically, with no need for dose modification.

With the mTOR inhibitors everolimus and temsirolimus, given the risk of dehiscence at the suture site, it is recommended that therapy be discontinued 7-10 days prior to surgery, and resumed not less than 3 weeks afterwards [52].

Last, during immunotherapy, the most common cutaneous toxicities are maculopapular rash, pruritus, and vitiligo. For clinical practice, it is suggested that grade 1 and mild grade 2 toxicities should be managed with supportive measures, and immunotherapy can continue. In the event of grade 3 or highly symptomatic grade 2 toxicities, the recommendation is to discontinue therapy temporarily until the symptoms become mild or have disappeared. It is then possible to resume it, once the risks and benefits have been discussed with the patient. With grade 4 toxicities, the therapy needs to be withdrawn permanently and the patient assessed urgently by a dermatologist [88].

Once the existence of cutaneous toxicity of grade 2 or above has been confirmed, the patient should be referred to the dermatology department, to commence specific treatment to improve the symptoms. Follow-up should take place. In the event of deterioration, the patient should be admitted to hospital and/or managed specifically as appropriate [81].

\section{Conclusions}

It is common for dermatological toxicities to occur while cancer patients are being treated with targeted therapies. Their onset may cause dose reductions and/or delays in treatment, thus compromising patient survival. Also, this toxicity has a significant impact on patients' quality of life and can affect their personal, social, and workplace relationships.

Cutaneous toxicity is most common with EGFR inhibitors, but it is not confined to this drug class. It also occurs with the use of TKIs, PDGFR, and BCR-ABL inhibitors, antiangiogenic drugs such as the monoclonal antibodies bevacizumab and ramucirumab, MAPK inhibitors, and immune checkpoint inhibitors, such as anti-CTLA-4 and anti-PD-1/ PD-L1 drugs.

The dermatological syndromes most often associated with these therapeutic targets are as follows: papulopustular eruption, the onset of which, in the case of anti-EGFR drugs, is related to greater overall survival; xerosis, and pruritus, sometimes combined with the above; hand-foot syndrome; rashes, often linked to multikinase inhibitors, and unrelated to efficacy in this case; abnormalities of the hair follicle 
and nail apparatus, linked to anti-EGFR drugs; pigmentary changes to the skin and its appendages; impaired healing due to antiangiogenic drug use; and neutrophilic dermatoses.

The toxicities most often caused by immunotherapy, with either anti-CTLA-4 or anti-PD-1/PD-L1 drugs, are maculopapular rash, pruritus, and vitiligo.

Whenever possible, these symptoms should be prevented. Accurate and prompt diagnosis is essential. Additionally, interdisciplinary cooperation between oncologists and dermatologists is critical to reduce the duration and severity of cutaneous toxicity, to optimize the delivery of therapy, and to improve patient survival.

Acknowledgements The authors are grateful for the editorial assistance of Fernando Sánchez-Barbero of HealthCo (Madrid, Spain) in the production of this manuscript. SEOM and AEVD are grateful for financial support for this project in the form of unrestricted grants from AstraZeneca, Avène, Boehringer Ingelheim, Pierre Fabre, Roche Farma, La Roche Posay.

\section{Compliance with ethical standards}

Conflict of interest The authors declare that, when writing and revising the text, they did not know the names of the companies that provided financial support for this project, so this support has not influenced the content of this article.

Ethical approval The study has been performed in accordance with the ethical standards of the Declaration of Helsinki and its later amendments. This article does not contain any studies with human participants or animals performed by any of the authors.

Informed consent All patients gave informed consent for the publication of their images that illustrate this article.

Open Access This article is distributed under the terms of the Creative Commons Attribution 4.0 International License (http://creativeco mmons.org/licenses/by/4.0/), which permits unrestricted use, distribution, and reproduction in any medium, provided you give appropriate credit to the original author(s) and the source, provide a link to the Creative Commons license, and indicate if changes were made.

\section{References}

1. Hammond-Thelin LA. Cutaneous reactions related to systemic immunomodulators and targeted therapeutics. Dermatol Clin. 2008;26:121-59.

2. Curry JL, Tetzlaff MT, Nagarajan P, Drucker C, Diab A, Hymes $\mathrm{SR}$, et al. Diverse types of dermatologic toxicities from immune checkpoint blockade therapy. J Cutan Pathol. 2017;44:158-76.

3. Li T, Pérez-Soler R. Skin toxicities associated with epidermal growth factor receptor inhibitors. Target Oncol. 2009;4:107-19.

4. Agero AL, Dusza SW, Benvenuto-Andrade C, Busam KJ, Myskowski P, Halpern AC. Dermatologic side effects associated with the epidermal growth factor receptor inhibitors. J Am Acad Dermatol. 2006;55:657-70.

5. Burtness B. Targeted agents: management of dermatologic toxicities. J Natl Compr Cancer Netw. 2014;12:793-6.
6. Peuvrel L, Dreno B. Dermatological toxicity associated with targeted therapies in cancer: optimal management. Am J Clin Dermatol. 2014; 15:425-44.

7. Robert C, Soria JC, Spatz A, Le Cesne A, Malka D, Pautier P, et al. Cutaneous side-effects of kinase inhibitors and blocking antibodies. Lancet Oncol. 2005;6:491-500.

8. Albanell J, Rojo F, Averbuch S, Feyereislova A, Mascaro JM, Herbst R, et al. Pharmacodynamic studies of the epidermal growth factor receptor inhibitor ZD1839 in skin from cancer patients: histopathologic and molecular consequences of receptor inhibition. J Clin Oncol. 2002;20:110-24.

9. Paul T, Schumann C, Rudiger S, Boeck S, Heinemann V, Kachele V, et al. Cytokine regulation by epidermal growth factor receptor inhibitors and epidermal growth factor receptor inhibitor associated skin toxicity in cancer patients. Eur J Cancer. 2014;50:1855-63.

10. Hu JC, Sadeghi P, Pinter-Brown LC, Yashar S, Chiu MW. Cutaneous side effects of epidermal growth factor receptor inhibitors: clinical presentation, pathogenesis, and management. J Am Acad Dermatol. 2007;56:317-26.

11. Chiang HC, Anadkat MJ. Isotretinoin for high-grade or refractory epidermal growth factor receptor inhibitor-related acneiform papulopustular eruptions. J Am Acad Dermatol. 2013;69:657-8.

12. Eilers RE Jr, Gandhi M, Patel JD, Mulcahy MF, Agulnik M, Hensing $\mathrm{T}$, et al. Dermatologic infections in cancer patients treated with epidermal growth factor receptor inhibitor therapy. J Natl Cancer Inst. 2010;102:47-53.

13. Pugliese SB, Neal JW, Kwong BY. Management of dermatologic complications of lung cancer therapies. Curr Treat Options Oncol. 2015;16:50.

14. Pérez-Soler R, Chachoua A, Hammond LA, Rowinsky EK, Huberman M, Karp D, et al. Determinants of tumor response and survival with erlotinib in patients with non-small-cell lung cancer. J Clin Oncol. 2004;22:3238-47.

15. Cunningham D, Humblet $Y$, Siena S, Khayat D, Bleiberg H, Santoro A, et al. Cetuximab monotherapy and cetuximab plus irinotecan in irinotecan-refractory metastatic colorectal cancer. New Engl J Med. 2004;351:337-45.

16. Soulieres D, Senzer NN, Vokes EE, Hidalgo M, Agarwala SS, Siu LL. Multicenter phase II study of erlotinib, an oral epidermal growth factor receptor tyrosine kinase inhibitor, in patients with recurrent or metastatic squamous cell cancer of the head and neck. J Clin Oncol. 2004;22:77-85.

17. Liu HB, Wu Y, Lv TF, Yao YW, Xiao YY, Yuan DM, et al. Skin rash could predict the response to EGFR tyrosine kinase inhibitor and the prognosis for patients with non-small cell lung cancer: a systematic review and meta-analysis. PLoS One. 2013;8:e55128.

18. Bachet JB, Peuvrel L, Bachmeyer C, Reguiai Z, Gourraud PA, Bouché $\mathrm{O}$, et al. Folliculitis induced by EGFR inhibitors, preventive and curative efficacy of tetracyclines in the management and incidence rates according to the type of EGFR inhibitor administered: a systematic literature review. Oncologist. 2012;17:555-68.

19. Pinta F, Ponzetti A, Spadi R, Fanchini L, Zanini M, Mecca C, et al. Pilot clinical trial on the efficacy of prophylactic use of vitamin K1-based cream (Vigorskin) to prevent cetuximab-induced skin rash in patients with metastatic colorectal cancer. Clin Colorectal Cancer. 2014;13:62-7.

20. Valentine J, Belum VR, Duran J, Ciccolini K, Schindler K, Wu $\mathrm{S}$, et al. Incidence and risk of xerosis with targeted anticancer therapies. J Am Acad Dermatol. 2015;72:656-67.

21. Ensslin CJ, Rosen AC, Wu S, Lacouture ME. Pruritus in patients treated with targeted cancer therapies: systematic review and meta-analysis. J Am Acad Dermatol. 2013;69:708-20.

22. Macdonald JB, Macdonald B, Golitz LE, LoRusso P, Sekulic A. Cutaneous adverse effects of targeted therapies: part II: inhibitors 
of intracellular molecular signaling pathways. J Am Acad Dermatol. 2015;72:221-36 (quiz 37-8).

23. Sankhala K, Mita A, Kelly K, Mahalingam D, Giles F, Mita M. The emerging safety profile of mTOR inhibitors, a novel class of anticancer agents. Target Oncol. 2009;4:135-42.

24. Conteduca V, Santoni M, Medri M, Scarpi E, Burattini L, Lolli C, et al. Correlation of stomatitis and cutaneous toxicity with clinical outcome in patients with metastatic renal-cell carcinoma treated with everolimus. Clin Genitourin Cancer. 2016;14:426-31.

25. Hueso L, Sanmartín O, Nagore E, Botella-Estrada R, Requena C, Llombart B, et al. Chemotherapy-induced acral erythema: a clinical and histopathologic study of 44 cases. Actas Dermosifiliogr. 2008;99:281-90.

26. Bolognia JL, Cooper DL, Glusac EJ. Toxic erythema of chemotherapy: a useful clinical term. J Am Acad Dermatol. 2008;59:524-9.

27. Chanprapaph K, Rutnin S, Vachiramon V. Multikinase inhibitor-induced hand-foot skin reaction: a review of clinical presentation, pathogenesis, and management. Am J Clin Dermatol. 2016;17:387-402.

28. Lacouture ME, Duvic M, Hauschild A, Prieto VG, Robert C, Schadendorf $\mathrm{D}$, et al. Analysis of dermatologic events in vemurafenibtreated patients with melanoma. Oncologist. 2013;18:314-22.

29. McLellan B, Kerr H. Cutaneous toxicities of the multikinase inhibitors sorafenib and sunitinib. Dermatol Ther. 2011;24:396-400.

30. McLellan B, Ciardiello F, Lacouture ME, Segaert S, Van Cutsem E. Regorafenib-associated hand-foot skin reaction: practical advice on diagnosis, prevention, and management. Ann Oncol. 2015;26:2017-26.

31. Boudou-Rouquette P, Narjoz C, Golmard JL, Thomas-Schoemann A, Mir O, Taieb F, et al. Early sorafenib-induced toxicity is associated with drug exposure and UGTIA9 genetic polymorphism in patients with solid tumors: a preliminary study. PLoS One. 2012;7:e42875.

32. Chen AP, Setser A, Anadkat MJ, Cotliar J, Olsen EA, Garden BC, et al. Grading dermatologic adverse events of cancer treatments: the common terminology criteria for adverse events version 4.0. J Am Acad Dermatol. 2012;67:1025-39.

33. Anderson R, Jatoi A, Robert C, Wood LS, Keating KN, Lacouture ME. Search for evidence-based approaches for the prevention and palliation of hand-foot skin reaction (HFSR) caused by the multikinase inhibitors (MKIs). Oncologist. 2009;14:291-302.

34. Manchen E, Robert C, Porta C. Management of tyrosine kinase inhibitor-induced hand-foot skin reaction: viewpoints from the medical oncologist, dermatologist, and oncology nurse. J Support Oncol. 2011;9:13-23.

35. Walko CM, Grande C. Management of common adverse events in patients treated with sorafenib: nurse and pharmacist perspective. Semin Oncol. 2014;41:S17-28.

36. De Wit M, Boers-Doets CB, Saettini A, Vermeersch K, de Juan CR, Ouwerkerk J, et al. Prevention and management of adverse events related to regorafenib. Support Care Cancer. 2014;22:837-46.

37. Huang X, Patel S, Ahmed N, Seiter K, Liu D. Severe toxicity of skin rash, fever and diarrhea associated with imatinib: case report and review of skin toxicities associated with tyrosine kinase inhibitors. Drug Des Dev Ther. 2009;2:215-9.

38. Nanney LB, Magid M, Stoscheck CM, King LE Jr. Comparison of epidermal growth factor binding and receptor distribution in normal human epidermis and epidermal appendages. J Invest Dermatol. 1984;83:385-93.

39. Busam KJ, Capodieci P, Motzer R, Kiehn T, Phelan D, Halpern AC. Cutaneous side-effects in cancer patients treated with the antiepidermal growth factor receptor antibody C225. Br J Dermatol. 2001;144:1169-76.
40. Rodeck U. Skin toxicity caused by EGFR antagonists-an autoinflammatory condition triggered by deregulated IL-1 signaling? J Cell Physiol. 2009;218:32-4.

41. Zheng H, Zhang H, Zhang T, Wang Q, Hu F, Li B. Trichomegaly and scalp hair changes following treatment with erlotinib in pulmonary adenocarcinoma patients: a case report and literature review. Exp Ther Med. 2016;12:1287-92.

42. Piraccini BM, Patrizi A, Fanti PA, Starace M, Bruni F, Melotti B, et al. RASopathic alopecia: hair changes associated with vemurafenib therapy. J Am Acad Dermatol. 2015;72:738-41.

43. Cario-André M, Ardilouze L, Pain C, Gauthier Y, Mahon FX, Taieb A. Imatinib mesilate inhibits melanogenesis in vitro. $\mathrm{Br}$ J Dermatol. 2006;155:493-4.

44. Arora B, Kumar L, Sharma A, Wadhwa J, Kochupillai V. Pigmentary changes in chronic myeloid leukemia patients treated with imatinib mesylate. Ann Oncol. 2004;15:358-9.

45. Balagula Y, Pulitzer MP, Maki RG, Myskowski PL. Pigmentary changes in a patient treated with imatinib. J Drugs Dermatol. 2011;10:1062-6.

46. McPherson T, Sherman V, Turner R. Imatinib-associated hyperpigmentation, a side effect that should be recognized. J Eur Acad Dermatol Venereol. 2009;23:82-3.

47. Sun A, Akin RS, Cobos E, Smith J. Hair depigmentation during chemotherapy with dasatinib, a dual Bcr-Abl/Src family tyrosine kinase inhibitor. J Drugs Dermatol. 2009;8:395-8.

48. Rosenbaum SE, Wu S, Newman MA, West DP, Kuzel T, Lacouture ME. Dermatological reactions to the multitargeted tyrosine kinase inhibitor sunitinib. Support Care Cancer. 2008;16:557-66.

49. Sibaud V, Robert C. Pigmentary disorders induced by anticancer agents. Part II: targeted therapies. Ann Dermatol Venereol. 2013;140:266-73.

50. Dalle S, Poulalhon N, Debarbieux S, Zaharia D, Mihm MC, Lacouture ME, et al. Tracking of second primary melanomas in vemurafenib-treated patients. JAMA Dermatol. 2013;149:488-90.

51. Scappaticci FA, Fehrenbacher L, Cartwright T, Hainsworth JD, Heim W, Berlin J, et al. Surgical wound healing complications in metastatic colorectal cancer patients treated with bevacizumab. J Surg Oncol. 2005;91:173-80.

52. Pignot G, Lebret T, Chekulaev D, Peyromaure M, Saighi D, Flam $\mathrm{T}$, et al. Healing and targeted therapies: management in perioperative period? Prog Urol. 2011;21:166-72.

53. Zhang H, Huang Z, Zou X, Liu T. Bevacizumab and woundhealing complications: a systematic review and meta-analysis of randomized controlled trials. Oncotarget. 2016;7:82473-81.

54. Macdonald JB, Macdonald B, Golitz LE, LoRusso P, Sekulic A. Cutaneous adverse effects of targeted therapies: part I: inhibitors of the cellular membrane. J Am Acad Dermatol. 2015;72:203-18 (quiz 19-20).

55. Wu BC, Patel ED, Ortega-Loayza AG. Drug-induced pyoderma gangrenosum: a model to understand the pathogenesis of pyoderma gangrenosum. Br J Dermatol. 2017;177:72-83.

56. Vázquez-Osorio I, Sánchez-Aguilar MD, García-Rodiño S, Suárez-Peñaranda JM, Aliste C, Vázquez-Veiga H. Vemurafenibinduced neutrophilic panniculitis: a new case and review of the literature. Am J Dermatopathol. 2016;38:e93-6.

57. Anforth R, Blumetti TC, Clements A, Kefford R, Long GV, Fernández-Peñas P. Systemic retinoids for the chemoprevention of cutaneous squamous cell carcinoma and verrucal keratosis in a cohort of patients on BRAF inhibitors. Br J Dermatol. 2013;169:1310-3.

58. Su F, Viros A, Milagre C, Trunzer K, Bollag G, Spleiss O, et al. RAS mutations in cutaneous squamous-cell carcinomas in patients treated with BRAF inhibitors. New Engl J Med. 2012;366:207-15.

59. Hauschild A, Grob JJ, Demidov LV, Jouary T, Gutzmer R, Millward M, et al. Dabrafenib in BRAF-mutated metastatic melanoma: 
a multicentre, open-label, phase 3 randomised controlled trial. Lancet. 2012;380:358-65.

60. Flaherty KT, Infante JR, Daud A, Gonzalez R, Kefford RF, Sosman J, et al. Combined BRAF and MEK inhibition in melanoma with BRAF V600 mutations. New Engl J Med. 2012;367:1694-703.

61. Zimmer L, Hillen U, Livingstone E, Lacouture ME, Busam K, Carvajal RD, et al. Atypical melanocytic proliferations and new primary melanomas in patients with advanced melanoma undergoing selective BRAF inhibition. J Clin Oncol. 2012;30:2375-83.

62. Hwang SJ, Anforth R, Carlos G, Fernández-Peñas P. Cutaneous adverse events of new anti-melanoma therapies: classification and management. Actas Dermosifiliogr. 2017;108:6-16.

63. Chu EY, Wanat KA, Miller CJ, Amaravadi RK, Fecher LA, Brose MS, et al. Diverse cutaneous side effects associated with BRAF inhibitor therapy: a clinicopathologic study. J Am Acad Dermatol. 2012;67:1265-72.

64. Gelot P, Dutartre H, Khammari A, Boisrobert A, Schmitt C, Deybach JC, et al. Vemurafenib: an unusual UVA-induced photosensitivity. Exp Dermatol. 2013;22:297-8.

65. Dummer R, Rinderknecht J, Goldinger SM. Ultraviolet A and photosensitivity during vemurafenib therapy. New Engl J Med. 2012;366:480-1.

66. Anforth R, Fernández-Peñas P, Long GV. Cutaneous toxicities of RAF inhibitors. Lancet Oncol. 2013;14:e11-8.

67. Zimmer L, Livingstone E, Hillen U, Domkes S, Becker A, Schadendorf D. Panniculitis with arthralgia in patients with melanoma treated with selective BRAF inhibitors and its management. Arch Dermatol. 2012;148:357-61

68. Yorio JT, Mays SR, Ciurea AM, Cohen PR, Wang WL, Hwu WJ, et al. Case of vemurafenib-induced sweet's syndrome. J Dermatol. 2014;41:817-20.

69. Herms F, Franck N, Kramkimel N, Fichel F, Delaval L, LaurentRoussel S, et al. Neutrophilic eccrine hidradenitis in two patients treated with BRAF inhibitors: a new cutaneous adverse event. Br J Dermatol. 2017;176:1645-8.

70. Spain L, Diem S, Larkin J. Management of toxicities of immune checkpoint inhibitors. Cancer Treat Rev. 2016;44:51-60.

71. Sheik Ali S, Goddard AL, Luke JJ, Donahue H, Todd DJ, Werchniak A, et al. Drug-associated dermatomyositis following ipilimumab therapy: a novel immune-mediated adverse event associated with cytotoxic T-lymphocyte antigen 4 blockade. JAMA Dermatol. 2015;151:195-9.

72. Pintova S, Sidhu H, Friedlander PA, Holcombe RF. Sweet's syndrome in a patient with metastatic melanoma after ipilimumab therapy. Melanoma Res. 2013;23:498-501.

73. Voskens CJ, Goldinger SM, Loquai C, Robert C, Kaehler KC, Berking C, et al. The price of tumor control: an analysis of rare side effects of anti-CTLA-4 therapy in metastatic melanoma from the ipilimumab network. PLoS One. 2013;8:e53745.

74. Vogel WV, Guislain A, Kvistborg P, Schumacher TN, Haanen JB, Blank CU. Ipilimumab-induced sarcoidosis in a patient with metastatic melanoma undergoing complete remission. J Clin Oncol. 2012;30:e7-10.

75. Hwang SJ, Carlos G, Wakade D, Byth K, Kong BY, Chou S, et al. Cutaneous adverse events (AEs) of anti-programmed cell death (PD)-1 therapy in patients with metastatic melanoma: a singleinstitution cohort. J Am Acad Dermatol. 2016;74(3):455-461.

76. Tetzlaff MT, Nagarajan P, Chon S, Huen A, Diab A, Omar P, et al. Lichenoid dermatologic toxicity from immune checkpoint blockade therapy: a detailed examination of the clinicopathologic features. Am J Dermatopathol. 2017;39:121-9.

77. Larsabal M, Marti A, Jacquemin C, Rambert J, Thiolat D, Dousset $\mathrm{L}$, et al. Vitiligo-like lesions occurring in patients receiving antiprogrammed cell death-1 therapies are clinically and biologically distinct from vitiligo. J Am Acad Dermatol. 2017;76:863-70.

78. Hwang SJ, Carlos G, Chou S, Wakade D, Carlino MS, Fernández-Peñas P. Bullous pemphigoid, an autoantibody-mediated disease, is a novel immune-related adverse event in patients treated with anti-programmed cell death 1 antibodies. Melanoma Res. 2016;26:413-6.

79. Sahuquillo-Torralba A, Ballester-Sánchez R, Pujol-Marco C, Botella-Estrada R. Pembrolizumab: a new drug that can induce exacerbations of psoriasis. Actas Dermosifiliogr. 2016;107:264-6.

80. Bonigen J, Raynaud-Donzel C, Hureaux J, Kramkimel N, Blom A, Jeudy G, et al. Anti-PD1-induced psoriasis: a study of 21 patients. J Eur Acad Dermatol Venereol. 2017;31:e254-7.

81. National cancer institute. Common terminology criteria for adverse events (CTCAE). 2017. https://evs.nci.nih.gov/ftp1/ CTCAE/CTCAE_4.03_2010-06-14_QuickReference_5x7.pdf. Accessed 19 Nov 2017.

82. Multinational association of supportive care in cancer. EGFR inhibitor skin toxicity tool (MESTT). 2017. http://www.mascc .org/mc/page.do. Accessed 19 Nov 2017.

83. Lacouture ME, Anadkat MJ, Bensadoun RJ, Bryce J, Chan A, Epstein JB, et al. Clinical practice guidelines for the prevention and treatment of EGFR inhibitor-associated dermatologic toxicities. Support Care Cancer. 2011;19:1079-95.

84. Petrelli F, Borgonovo K, Cabiddu M, Lonati V, Barni S. Relationship between skin rash and outcome in non-small-cell lung cancer patients treated with anti-EGFR tyrosine kinase inhibitors: a literature-based meta-analysis of 24 trials. Lung Cancer. 2012;78:8-15.

85. Lakomy R, Poprach A. Side effects of modern immunotherapy and how to solve them in the clinics. Klin Onkol. 2015;28:4S103-14.

86. Weber JS, Kahler KC, Hauschild A. Management of immunerelated adverse events and kinetics of response with ipilimumab. J Clin Oncol. 2012;30:2691-7.

87. Aragón Manrique I, Bayo Calero J, Bolaños Naranjo M. Oncobiomecum. Madrid: You \& US; 2014.

88. Haanen J, Carbonnel F, Robert C, Kerr KM, Peters S, Larkin $\mathrm{J}$, et al. Management of toxicities from immunotherapy: ESMO clinical practice guidelines for diagnosis, treatment and follow-up. Ann Oncol. 2017;28:iv119-42. 